\title{
Enhancement of PVC/ENR Blend Properties by Poly(methyl acrylate) Grafted Oil Palm Empty Fruit Bunch Fiber
}

\begin{abstract}
Effect of oil palm empty fruit bunch(OPEFB) fiber and poly(methyl acrylate) grafted OPEFB on several mechanical properties of poly(vinyl chloride)/epoxidized natural rubber (PVC/ENR) blends were studied. The composites were prepared by mixing the fiber and the PVC/ENR blends using HAKEE Rheomixer at the rotor speed of $50 \mathrm{rpm}$, mixing temperature $1508 \mathrm{C}$, and mixing period of $20 \mathrm{~min}$. The fiber loadings were varied from 0 to $30 \%$ and the effect of fiber content in the composites on their ultimate tensile strength (UTS), Young's modulus, elongation at break, flexural modulus, hardness, and impact strength were determined. An increasing trend was observed in the Young's modulus, flexural modulus, and hardness with the addition of grafted and ungrafted fiber to the PVC/ENR blends. However the impact strength,UTS, and elongation at break of the composites were found to decrease with the increase in fiber loading. An increase in elongation at break and UTS and decrease in the flexural and Young's modulus was observed with the addition of PMA-gOPEFB fiber compared to ungrafted fiber. This observation indicates that grafting of PMA onto OPEFB impart some flexibility to the blend. The morphology of cryogenically fractured and tensile fracture surfaces of the composites, examined by a scanning electron microscope shows that the adhesion between the fiber and the matrix is improved upon grafting of the OPEFB fiber.
\end{abstract}

Keyword: grafting, OPEFB fiber, poly(methyl-acrylate), PVC/ENR blend, mechanical properties 